multidisciplinary panels. • Stakeholders- Using multi-tiered approach to involve stakeholders via Consultation, Participation, and Communication models and outreach to mental health peer support programmes. - Systematic Reviews- Applied Delphi poll method in topic scoping/refinement to work within organisational resources. Other mechanisms to enhance resources include topic nominations to AHRQ, possible organisational partnerships, and developing products from guidelines. EducationCreating a series of self-study educational modules on guideline development.

Lessons for Guideline Developers and Others Our challenges and resolutions could be helpful to others in guideline development.

\section{P227 CAPACITY ENHANCEMENT THROUGH A DISTANCE LEARNING COURSE FOR PRIMARY HEALTH CARE (PHC) PROFESSIONALS: THE FIRST APPROACH FOR A GUIDELINE DEVELOPMENT}

A Stein, E Wendland, M Pinto, O D'Avila, A Dahmer. Department of Public Health UFCSPA, Porto Alegre, Brazil

\section{0:1136/bmjqs-2013-002293.217}

Background There is a need to develop strategies for guideline development. It is essential to learn educational needs of health professionals who work at PHC level. Evidence based guidelines should be applied for these health professionals taking into account their context.

Objectives To identify skills and resources of primary health professionals in a distance learning course (UNASUS from UFCSPA - Federal University of Health Science of Porto Alegre).

Methods A quasi-experiment study had been carried out and the inclusion criteria were dentists, nurses and family physicians that provide PHC. Data had been collected in the beginning of the distant course, as a baseline and one year after the enrollment. This course enables specialisation for primary health care. A web-based questionnaire was applied to these subjects.

Results The sample size was 251 eligible subjects. The mean age of the responders was 35.2 \pm 8.27DP (range: 25-68), from 48 different towns from South Brazil. The majority (88.8\%) were women and $67.3 \%$ had nurse degree. $94 \%$ of the subjects reported that the distance course was a good strategy to change their practice. Interactive activities resembling their daily routine had a higher impact.

Discussion The results have shown that distance learning is effective to enhance primary health care professional's behaviour, especially when simulating real cases.

Implications for guideline developers/users The present research has identified that it is essential to improve access to evidencebased clinical practice guidelines and resources across Brazil, and to increase skill capacity in using evidence to inform clinical decision-making.

\section{P233 HOW CONFIDENT ARE YOU IN THE RESULTS GIVEN ONLY ONE RCT? TICAGRELOR VS CLOPIDOGREL: CASE REPORT BY CLINICAL GUIDELINE ON ACUTE CORONARY SYNDROME IN COLOMBIA}

N Acosta-Baena, L Lugo, A Mejia, J Senior. Universidad de Antioquia, Medellin, Colombia 10:1136/bmjqs-2013-002293.218
Background Ticagrelor is oral antagonist of adenosine diphosphate receptors of subtype P2Y12. It is indicated for the prevention of atherothrombotic events in adults with acute coronary syndromes (ACS) and it act faster and shorter than clopidogrel.

Objectives The authors review and discuss clinical findings and health-economic evidence of ticagrelor compared with clopidogrel to reduced myocardial infarction, stroke or death, major bleeding, in patients with ACS in Colombia, when only one RCT has been published comparing both drugs.

Methods This question was part of the guideline development. The process included search, assessment, rating the quality of evidence and economic evaluation. The recommendations were classified according to the methodology described by GRADE Working Group: consideration benefit/harm, preferences and resources.

Results 1 clinical study was identified. The efficacy outcome was favourable for the group of patients receiving ticagrelor. The result of the economic analysis suggests that the probability of ticagrelor is a cost effective alternative in the Colombian health system is more than $76.6 \%$.

Discussion We recommend ticagrelor plus ASA for patients with non-STEMI, intermediate to high-risk, and for patients with STEMI if they have not received fibrinolysis in the last 24 hours.

Implications for Guideline Developers/Users Our results hold in different scenarios and sensitivity analyses, as long as the time horizon is not limited to short-term assessment because may underestimate the costs and benefits and therefore lead to erroneous conclusions with a single primarily study. Our recommendation is strong, although there was a single RCT owing to time horizon and high quality of evidence.

\section{P235 FROM CLINICAL PRACTICE GUIDELINES TO THE COMPREHENSIVE CARE GUIDELINE FOR PATIENTS: BEYOND THE SCIENTIFIC PROCESS, A TASK OF CULTURAL CONSTRUCTION}

L Bonilla Mahecha, M Moreno, P Mosquera, H Gaitan. Universidad Nacional de Colombia, Bogota, Colombia

\section{0:1136/bmjqs-2013-002293.219}

Background Patients guideline development is a complex process that must combine harmoniously clinic expert knowledge, values, preferences and patient's information needs; it means in itself the possibility of transforming social imaginary, practices, beliefs and behaviours health. The design of a qualitative methodology systematic and rigorous a guideline for patients would allow producing efficient results. The paper contains the design of a systematic and rigorous type of qualitative methodology, a guidelines for patients, was allowed producing efficient results.

Objective Design a methodology for patients' guidelines development in the Colombian context.

Methods A qualitative type study was developed in three phases: 1) Review of materials and patients guidelines targeting populations, creating an array of identification of information needs. 2) Development of a proposal for a context-sensitive communication expert team. 3) Validation of contents.

Results Designed a methodology with ten steps and developed the guidelines for patients which included scientific evidence, socio-cultural practices and participation of patients. The validation of the sexually transmitted infections the Guide was attended to people with a variety of gender, age and educational 